\title{
An evaluation of general practitioners' knowledge and satisfaction of a local child and family psychiatric service
}

\author{
Aristos Markantonakis, Senior Registrar in Child and Adolescent Psychiatry, and \\ JoHn MathaI, Consultant in Child and Adolescent Psychiatry, The Institute of \\ Family Psychiatry, 23 Henley Road, Ipswich IP1 3TF, Suffolk
}

\begin{abstract}
Although childhood psychiatric disorders are commonly seen in general practice, only a few children in the community eventually gain access to professional help (Rutter, Cox, Tupling et al, 1975; Bailey, Graham \& Boniface, 1978). Whether a child is referred or not depends on various factors connected with the child and family (Garralda \& Bailey, 1988) and others such as what the GP expects from the referral. Whether GPs know of what the child psychiatric services in the area have to offer might also be expected to effect referral. We know that there is a general dissatisfaction with written communication between general practitioners and specialists in terms of the quality on the communication and usefulness to both groups (Pullen \& Yellowlees, 1985; Kentish, Jenkins \& Lask, 1987).
\end{abstract}

\section{The study}

The aim of the study was to assess the standard of knowledge of general practitioners about the available child and family psychiatric services in their area and their level of satisfaction of this service in terms of its accessibility and communication. Their suggestions as to how the service could be improved were also noted. An attempt was made to assess the amount of difficulty that GPs have experienced in persuading their patients to accept referral to child psychiatrists and the possible reasons for their resistance. Finally, as we provide a service to other agencies, we asked GPs if they felt it would be appropriate for psychiatrists to receive referrals directly from agencies not related to primary medical care, e.g. social services, probation services etc.

\section{The service}

The Department of Child Psychiatry is based at the Institute of Family Psychiatry in Ipswich. The Institute has three full-time consultant psychiatrists, two senior registrars and one registrar. There are in addition one and a half clinical psychologists and occupational therapists. The Institute accepts patients of all age groups, the main diagnostic category being neurosis. The following service is provided to a population of approximately 315,200 living in a large and rural area: family and marital therapy; individual psychotherapy for children; group psychotherapy for children and adolescents; group therapy for parents; individual psychotherapy for adults; in-patient service of disturbed adolescents. There is no provision for in-patient treatment of psychologically disturbed children.

\section{Findings}

Out of 160 questionnaires sent out to all the GPs in the area of East Suffolk Health District, 123 were returned, a response rate of $77 \%$.

\section{(a) Awareness of our service?}

Of the GPs who took part in the survey, $83 \%$ were aware that we hold regular courses for them. However, $33 \%$ of the GPs who returned their questionnaire were unaware of our adolescent unit and $44 \%$ thought, mistakenly, that we were providing an in-patient treatment for disturbed children! Only $18 \%$ of the GPs correctly knew that we provide an in-patient service for adolescents and not for children.

\section{(b) Accessibility and communication?}

Seventy-six per cent of the GPs felt that we were accessible enough to them and their patients. The most common reasons given by the minority who felt that we were inaccessible were long waiting lists and difficulties with transport. A larger number $(92 \%)$ of GPs felt that communications between us and them were very good to average. "More follow-up letters" was the most common suggestion for improving communications.

\section{(c) Resistance to referral?}

Stigma attached to the psychiatric label was the most common reason (67\%) given by the GPs for their patients resisting referral. Forty-five per cent of the GPs felt that they had experience of patients refusing referral or raising significant objections before accepting referral. 


\section{(d) Referrals from other agencies?}

The possibility of not being informed or involved in referral was the most common reason given by $45 \%$ of the GPs who felt it would be inappropriate for us to accept referrals from agencies not related to primary medical care.

\section{Comment}

Despite the well publicised dissatisfaction with written communication between GPs and specialists, we found from our study that most general practitioners in our area felt communication was good or average; we were surprised therefore to see that $33 \%$ of the GPs who returned our questionnaire were unaware of our adolescent unit. We ask whether this might be because GPs were not usually involved directly in admissions as these were often arranged by the consultant child psychiatrist? However, many were also unaware of other existing services such as group psychotherapy for children $(38 \%)$, group psychotherapy for parents $(39 \%)$ and individual psychotherapy for adults (56\%). Nearly all GPs $(99 \%)$ knew that family therapy was provided at the "Institute of Family Psychiatry". Forty-four per cent of the GPs mistakenly believed that we were providing an in-patient service for psychologically disturbed children. Cross-tabulation of these results showed that GPs who were unaware of the adolescent unit were different GPs to those who assumed that we have an in-patient service for psychologically disturbed children. This was more worrying to us as it suggested that there was a bigger number of GPs who were misinformed. Nearly a quarter felt that long waiting lists, lack of transport facilities, inconvenience and cost of travelling made us inaccessible. We know from clinical experience that it is a useful indicator of motivation if patients are willing to suffer some inconvenience and pay costs of travelling to gain access to professional help. We were not surprised to see that stigma was the most significant reason for patients refusing referral. We have always been aware of the power of stigma as a barrier to treatment and the need for educating the public about psychiatry and psychiatrists. From our experience of teaching, even professionals are unaware of the difference in the roles of psychologists and psychiatrists.

Most GPs see themselves as central in the provision of care to patients in primary medical care. Forty-five per cent felt it would be inappropriate for us to receive referrals directly from other agencies and the most common reason for this was the fear that they might be left in the dark about a referral having been made to us. Some were concerned that we may be overwhelmed by inappropriate referrals.

Clearly there is a need for GPs to be made more aware of the services that we have to offer. This could perhaps be achieved by holding an open-day for GPs, or by sending a leaflet to them pointing out current available services. However, leaflets tend to be notoriously unread! Education of the public could be improved through the school system and the media. It would be interesting to carry out this survey in different regions of the country and compare general practitioner awareness.

\section{Acknowledgements}

We would like to thank Dr Bill Smith, Consultant Community Physician and Mr Peter Smith for their help in the formation of the questionnaire.

\section{References}

Bailey, V., Graham, P. \& Boniface, D. (1978) How much child psychiatry does a general practitioner do? Journal of the Royal College of General Practitioners, 28, 621-626.

GarRalda, M. E. \& Bailey, D. (1988) Child and family factors associated with referral to child psychiatrists. British Journal of Psychiatry, 153, 81-89.

Kentish, R., Jenkins, P. \& Lask, B. (1987) Study of the written communication between general practitioners and departments of child psychiatry. Journal of the Royal College of General Practitioners, 37, 162-163.

PUlleN, I. M. \& YellowleEs, A. J. (1985) "Is communication improving between general practitioners and psychiatrists?" British Medical Journal, 290, 31-34.

RutTer, M., Cox, A., Tupling, C., Berger, M. \& Yule, W. (1975) Attainment and adjustment in two geographical areas. I. The prevalence of psychiatric disorder. British Journal of Psychiatry, 125, 493-509. 